\title{
From teaching literacy to teaching numeracy: How numeracy teacher's previous experiences shape their teaching beliefs
}

\author{
SONJA BEELI-ZIMMERMANN
}

\begin{abstract}
Beliefs guide teachers' actions in the classroom and thereby influence what students learn. While this insight has led to numerous studies, particularly in the area of mathematical beliefs, it has been neglected in the growing field of numeracy teaching and learning within adult education. This exploratory study presents five illustrative cases of Swiss adult education teachers and traces their experiences, both as students and teachers. Based on data mainly collected in semi-structured interviews, the author argues that this study supports existing evidence from mathematical belief research in other sectors of education, pointing to the relevance of practice-based experiences for the change of beliefs.
\end{abstract}

\section{Introduction}

Both students' and teachers' beliefs play a central role in what happens in the classroom: they are not only relevant for an individual's learning, but equally influential in the implementation (or lack thereof) of curricular reforms (Handal \& Herrington 2003). It is therefore not surprising that 'beliefs now constitute "a no longer hidden variable" in research on ... teaching and learning' (Goldin, Rösken \& Törner 2009:14). This is particularly true in the field of mathematics education. But while mathematical belief research in the context of school has received considerable attention in the past decades, particularly at the level of primary school (Forgasz \& Leder 2008), it has almost gone unnoticed in the field of adult education: neither the seminal work on mathematical beliefs (Leder, Pehkonen \& Literacy and Numeracy Studies 2015. (C) 2015 SONJA BEELI-ZIMMERMANN. This is an Open Access article distributed under the terms of the Creative Commons Attribution 4.0 Unported (CC BY 4.0) License (https://creativecommons.org/licenses/by/4.0/), allowing third parties to copy and redistribute the material in any medium or format and to remix, transform, and build upon the material for any purpose, even commercially, provided the original work is properly cited and states its license. 
Törner 2002a) nor the most recent discussion on the current state of mathematical belief research (Hannula, Portaankorva-Koivisto, Laine \& Näveri 2012) explicitly discuss its relevance nor implications in adult education. Two exceptions are Stone (2009) who examined how the institutional context affects numeracy teachers' beliefs and classroom practice, and Henningsen and Wedege (2003) who looked at attitudes among mathematics teachers in adult education.

Furthermore, a number of studies exist which address either general beliefs of adult education teachers (Pratt 1992; Dirkx \& Spurgin 1992) or specific beliefs such as teaching principles of numeracy teachers (Swain \& Swan 2009). However, as Schlöglmann (2007) has pointed out, the study of adults learning mathematics is a rapidly growing field - a field within which numeracy holds a special place, not least of all because low numeracy skills are associated with a number of negative issues such as low-skilled occupation and therefore also lower earnings (OECD 2013).

This article presents five cases from a specific and growing group of teachers in Switzerland: teachers of adult education who teach numeracy or address mathematical issues in their literacy classes. More specifically, it looks at select moments in the teachers' lives and how the experiences in these moments might have influenced their acquisition and change of beliefs. Similar approaches, namely looking at teachers' own experiences and relating them to the individuals' beliefs have previously been used in a number of cases (Kaasila, Hannula, Laine \& Pehkonen 2006, Millsaps 2000, Perkkilä 2003, Taylor 2003).

\section{Mathematical belief research}

While there is no accepted definition of beliefs, there is agreement that beliefs include both cognitive and affective elements, are structured, function as filters, and impact on an individual's actions (Pajares 1992, Grigutsch, Raatz \& Törner 1998, Furinghetti \& Pehkonen 2002, Goldin, Rösken \& Törner 2009). Teachers' beliefs are therefore instrumental to their practice and students' learning. This insight has been reflected in an increased research interest in teacher's cognition since the 1970s (Calderhead 1996). Beliefs can be held in relation to a variety of issues, ranging from general beliefs about pedagogy and learning to beliefs about specific subjects or areas within a subject. With respect to beliefs about mathematics, there is broad agreement that there is not one right (and several wrong) 
view(s) of mathematics, rather philosophers of mathematics have described several ways of seeing the field (Leder, Pehkonen \& Törner 2002b).

Many studies have been conducted on the basis of what the philosopher of mathematics education Ernest (1989) identifies as three views of mathematics, namely: (i) an instrumentalist view that sees mathematics as a useful but unrelated collection of facts, rules and skills; (ii) a problem-solving view which considers mathematics to be a dynamic and continually changing and expanding field of human inquiry; and (iii) a Platonist view which describes 'mathematics as a static but unified body of knowledge, consisting of interconnecting structures and truths' (p 21). Ernest (1989) further postulates that mathematical beliefs impact on the teaching of mathematics, more specifically that different teacher roles, such as that that of an instructor, facilitator or explainer, are likely to correspond to these contrasting views of mathematics. However, many studies examining the relationship between mathematical beliefs and teaching merely differentiate between what is generally called a modern constructivist orientation to teaching and a traditional transmission orientation (Raymond 1997, and more recently Barkatsas \& Malone 2005). While there are studies which describe further types, for example Askew and his colleagues (Askew, Rhodes, Brown, William \& Johnson 1997) who identified an additional view of teaching mathematics that they called connectionist, it seems that the distinction 'between the transmission orientation and the remaining two constructivist orientations' (Swan 2006:61) is more pronounced than the distinction between the two constructivist orientations.

One area of belief research which is still considered to be 'open' (Pehkonen 2008:1) is that of changes in teachers' beliefs. Beliefs are formed and changed through an individual's social environment; they can therefore be considered to be a product of socialisation. More specifically, it is often argued that future teachers enter teacher education with beliefs which are shaped by their own educational experiences and that the latter are often more influential than what teachers have learned in their teacher training courses (Forgasz \& Leder 2008). It is also worth noting that many studies, particularly those examining beliefs of pre-service or novice teachers, are looking at particularly homogenous groups of people: their participants not only had very 'accordant experiences of school and 
teaching and therefore enter teacher education with largely similar beliefs' (Blömeke, Müller, Felbrich \& Kaiser 2008:323, translation by the author); they have also undergone the same teacher education program which further contributes to their homogeneity.

Teacher education holds an important place in belief research and many studies (sometimes implicitly) conclude that this phase of a teacher's life has the potential to play a key role when it comes to changing beliefs. However, beliefs are generally considered to be hard to change, as they have not only been formed over a long period of time (Andrews \& Hatch 1999), but are also part of a larger system of beliefs about the world (Pajares 1992). It is therefore not surprising that many authors conclude that 'teachers, in spite of courses and workshops, are most likely to teach math just as they were taught' (Ball 1988:2, similarly Handal 2003).

Taylor who examined the relationship between the school lives of adult educators and their beliefs about teaching adults found 'little discrepancy from the participants' perception of their past school lives and their present beliefs about teaching adults' (2003:75). Studies showing that change does happen often refer to practical experiences - ideally combined with opportunities for reflection which have a positive effect on belief change (van Zoest, Jones \& Thornton 1994, Ambrose 2004). However, overall empirical results with regard to the change of beliefs are inconclusive, something which might also be due to the absence of long term studies in belief research.

From a methodological perspective, belief research covers a wide variety of methods and uses both qualitative and quantitative approaches with interviews and questionnaires as the most prominent instruments for collecting data. However, there are also studies using videotaped classroom sessions, teachers' diaries, planning instruments and concept maps (Calderhead 1996). Forgasz and Leder (2008) noted that while small scale qualitative studies dominate research on primary teachers and large scale quantitative studies using data collected with questionnaires and surveys tend to remain at the descriptive level. Moreover, Speer (2005) asserts that the use of specific research methods has an impact on the much debated question of the relationship between teachers' professed and enacted beliefs, namely that that any 'perceived discrepancy [...] may actually be an artefact of the methods used to collect and analyse relevant data' (Speer 2005:361). 
One challenging aspect of belief research is the fact that beliefs entail subconscious elements which are not easily revealed (Pehkonen \& Törner 2004). Various methods such as the use of metaphors (Berger 1999, Oksanen \& Hannula 2012), drawings (Bulmer \& Rolka 2005, Rolka \& Halverscheid 2011) and photographs (Taylor 2002) have been employed in order to overcome this challenge. Likewise, data and method triangulation (Pehkonen \& Törner 2004, Swan 2006) have been found to be effective approaches to belief research.

In short, the basis of this study are the three views of mathematics as they are described by Ernest (1989) and refers to views of teaching as being either constructivist or traditionalist oriented. It builds on the assumption that beliefs are shaped by an individual's previous experiences - both as students and teachers. It furthermore uses both qualitative and quantitative data based on research instruments developed and previously used by Rolka and Halverscheid (2011) and Swan (2006). In line with these research instruments it also adopts these authors' understanding of beliefs as world views and uses these terms interchangeably.

\section{The research project}

\section{Context}

While numeracy classes for adults are an integral element of adult education in many countries, this is not (yet) the case in Switzerland. Dedicated numeracy classes for adults are few and far between. However, an increasing need to teach not only literacy to people with low qualifications has led to the development of a targeted training in numeracy teaching in German speaking Switzerland. The fourth of these training courses has taken place in the winter of 2013/2014 and some 45 individuals have been trained as numeracy teachers since its inception in 2010.

The course which consists of eight full days of training combined with a practical project is spread over six months and is aimed at people with a basic degree in adult education ${ }^{1}$ who are planning to teach numeracy or include numerical aspects in their language classes. A majority of the participants are people who are teaching German as a second language and are therefore often working with migrants or individuals with low levels of education. Discussing issues with mathematical elements, such as shopping and reading time tables - or more generally managing money and time - 
is an integral part of their classes, as the ultimate aim of their courses is the students' integration into the Swiss workforce. The mathematical content they are teaching is therefore often referred to as 'everyday mathematics'.

Complementary to this new training course for adult education teachers, an informal network called 'Network for everyday mathematics' has been founded (from now on referred to as the network $)^{2}$. It brings together most of the former course participants as well as other individuals interested in this field. Through this network regular events are organised and an online platform offers the opportunity to exchange ideas, material and discuss specific questions. All five cases reported in this article reflect this rapidly developing context as all of them have been teaching German as a second language for a while before moving into teaching 'everyday mathematics'. Furthermore, all of the participants have not only undergone the first or second of the new numeracy training programmes, but are also members of the network.

In order to reflect the terminology as it is used in the Swiss context, the terms 'everyday mathematics' and 'numeracy' will be used synonymously throughout this article. While acknowledging that this use obliterates some conceptual differences of the terms (see Condelli 2006), it seems more important and appropriate to stress their difference from mathematics (O'Donoghue 2002), rather than the finer distinctions between numeracy and everyday mathematics. Therefore, whenever the former terms are used, they refer to the specific working contexts as experienced by the study participants, whereas the term 'mathematics' refers to the more general domain of knowledge.

\section{Methodology and data}

The overall approach of this study is an exploratory one and it is based mainly on qualitative methods, but also using data and method triangulation. Triangulation is understood - and therefore pursued - not only in the sense of its primary scientific purpose of validating specific findings and identifying "'three sides' by which to approach the world'(Richardson \& St Pierre 2005:963); it is also used because different perspectives do offer an opportunity for different insights as there are certain blind spots for each method.

Data collected include a picture drawn by the participants, an approach based on the work by Rolka and Halverscheid (2011); two 
semi-structured interviews; and a short survey taken from an instrument developed by Swan (2006). The task given to the participants that led to their production of the picture was sent to the participants and they created it in advance of the first interview. It was then used as cue for the first interview (see annex 1 for details). The two interviews were based not only on the picture, but involved specific questions related to teaching adults. Furthermore, the interviews retraced the participants' own educational biography and tried to elicit their memories and teaching beliefs by letting them comment on video sequences from select mathematics classes (unterrichtsvideos 2008ff). Swan's questionnaire, which the participants completed on paper at the end of the second interview in the presence of the author, mainly explores teaching beliefs and is based on Askew's and his colleagues' (1997) tripartite view of teaching (see annex 2 for the part also used in this study). In addition, the author participated in some meetings of the network to inform her understanding of the wider context of the participants' teaching.

Both the pictures and the interview transcripts were analysed with the method of qualitative content analysis as described by Mayring $(2000,2013)$. This method allows for a systematic analysis of data as it is based on explicit rules for coding. Codes can be derived in a deductive or inductive manner, taking into account previously generated knowledge and theories as well as being open to issues arising from the material. More specifically, the pictures were analysed with a list of criteria developed by Rolka and Halverscheid (2011). They described visual key characteristics for each of Ernest's views which allow for a rough classification of visual data. For example, according to these criteria, pictures showing an instrumentalist view of mathematics need to display non-coherent sequences and illustrate the usefulness or application of mathematics in everyday life (see annex 3 for a brief presentation of their complete coding scheme and Beeli-Zimmermann 2014 for a detailed analysis of all pictures created by the participants of this study).

Most of the data were collected in the summer of 2012. The focus of the data used for this article is on the material generated through the-semi structured interviews, particularly the second interview. A key question in this interview was 'How did you arrive at the position you are in today?' where participants were asked to recount their own education with a table summarising the main steps of the educational system in Switzerland as aide memoire. ${ }^{3}$ 
Furthermore any references to their previous experiences, as they were made throughout the interviews, were included in the reconstruction of their educational biography. All statements relating to their personal experiences were either coded with the code called 'memories as student' or the one called 'memories as teacher'. Statements which included phrases such as 'my memory from this time ...', 'when I was ...' or 'I know from my students ...' were typically allocated to one of these two codes. Both of these codes contain a number of sub-codes, such as 'positive experience', 'negative experience' or 'specific areas of mathematics' which help to analyse the material in more detail.

\section{Participants}

All of the participants were recruited through the network and volunteered to participate in the study. While in total eight people took part, only those five individuals who teach German as a second language and participated in the numeracy training are presented in this paper. At the time of the study, they were between 45 and 57 years old; three of them were male, two female. As there is no initial standard training in adult education in Switzerland, all of them became adult education teachers only after being trained and working in other fields. As will be shown, teaching numeracy has not been a deliberate choice of career for any of them, but rather something that happened incidentally. More detailed portraits of the participants, including their arrival at teaching numeracy, are presented in the next section.

\section{Results}

The results will be described in three parts: first the five cases will be presented in more detail in form of short portraits (all names changed by the author). These portraits are based on the recount of the participants' educational biography. Afterwards two key aspects of their biographies are illustrated with more details, namely their own school experiences and their experiences teaching adults. In the third section, their mathematical and teaching beliefs are presented in more detail including references to the visual and quantitative data in order to arrive at a wholistic picture. All quotes are translated from German by the author and an effort was made to keep the tone of the portraits as close to the participants' as possible, by keeping the original 
vocabulary and phrases whenever possible and retaining the colloquial tone of unfinished sentences.

\section{Participant portraits}

Lucy's (57 years old) first educational qualification was as a commercial clerk. After working in this field, she owned her own company dealing with computers before studying French and English to become a translator. She then attended jazz school before moving into adult education where she is now mainly teaching German as a second language for beginners. It is in this context that she also teaches numeracy. Lucy considers numeracy to be 'applied mathematics ... it is only about things that one can use'. This fits with what she considers to be her main task when teaching, namely

to help them [her students] with their social and occupational integration in Switzerland [...] and certain things such as managing time or money have to do with mathematics and are part of this.

When teaching she thinks it is important for students to understand this usefulness because 'it needs to generate a motivation for them to learn.' Lucy is very responsive to her students' needs and uses individualised methods which challenge the students, but are neither too difficult nor too easy. 'I never, never teach the same way twice ... I can't do it twice, identically, because it has to emerge from the dialogue with the people'. Her own school experiences were - as far as she remembers - mainly positive. With regard to mathematics, she says, 'in high school I started floundering pretty soon ... but it didn't worry me, because I knew I could give up mathematics'. A career consultant once told her parents that her ability for abstract thinking was limited and so she said 'in the second year I thought, well my abstract thinking is limited ... so this is the end of it. Without stressing about it'. She enjoys solving puzzles and quizzes -

with relish, because it [mathematics] is interesting, like a crossword, it is a brainteaser and I enjoy doing it and where it is beyond me, it is no longer stressful, as I don't have to be able to do it anymore.

What Lucy likes about mathematics is its regularity and symmetry: 'Mathematics is an exact science, it's always the same ... this regularity and structure, ... symmetry is mathematics'.

Daniel (53 years old) is a trained chemical technician who worked in the industry for more than a decade before he travelled 
around France and Spain as a manual worker. After returning to Switzerland he trained as a forest engineer and then worked outdoors with various groups of people such as youth or former drug addicts. He is currently employed in the social services department of a large city where he works with unemployed people. Because mathematical qualifications are increasingly more relevant for their employability, Daniel is also teaching numeracy.

While working outdoors he developed the conviction that 'onsite education can be very efficient. You have the material, you can show it, try it out'. This is also his approach to teaching numeracy. He goes to his students' workplace and: 'I like to take something from the shelf, [and ask] how much volume contains this tin, what is in it, ... and then they ask and some themes emerge'. For him, the students' questions and interests are key: 'The aim is to find out what their questions are, what they are interested in ... material is secondary, it is about getting their attention, their interest'. He therefore sees his role to be that of an adviser and a door opener.

Daniel's attitude towards mathematics is very ambivalent: he really likes some aspects such as its application in chemical and physical contexts - the way he also experienced it during his apprenticeship - or the beauty of mathematical regularities found in nature. But he strongly dislikes the social filtering aspect that mathematics can have, particularly in school: 'Either you can do itor not. And you are stupid, if you can't do it [school is] really oriented towards errors, there is nothing appreciative in it'. He experienced these two positions during his own school time, about which he says:

I had good experiences in primary school [...] in secondary school it all went downhill rapidly [...] and then this apprenticeship, without it I would now probably also be somewhere in a programme for the integration of unemployed, but on the other side, as a participant.

Kathrin (52 years old) has been educated and worked briefly as a primary school teacher. Afterwards she took a year off to ' $d o$ fun things which have nothing to do with maths, well, maybe. As I know today, everything has to do with maths!'. She then trained and worked as a speech therapist before moving into adult education. She currently works as adult education teacher as well as a speech therapist. While working in adult education, numeracy became 
increasingly important 'and then I thought, oh well, why don't you complete this training [for numeracy teachers].'

For Kathrin, both language and mathematics 'are nothing else but action ... everyday maths, maths in the environment, always related to reality ... it's not about stacking numbers, it's about finding solutions'. She sees mathematics as being 'limitless and touching everything ... everything is connected and somehow saturated [with maths]'. She thinks mathematics has something playful and at school she liked the comfort and feeling of achievement that routine tasks provided - even though in her secondary school she also experienced the limits of her preferred approach of 'listening to the teacher and following the recipe'. Still, her own school experiences were very positive, she was always a good student and well-liked by both teachers and peers as she often helped them with their homework (for example constructing their geometry tasks in their exercise books in the morning before class). Kathrin's view of mathematics was also shaped by her son's learning history as well as a colleague who, as a remedial teacher 'loved maths and could create magic or the paradise with it'. When teaching numeracy to adults, it is of utmost importance to her to listen very carefully and 'to be very attentive at the beginning, to find out subtle differences [between the students' abilities] and who can do what'. She wants to know 'where the shoe pinches' in order to afterwards set adequate tasks.

Paul (43 years old) is a self-employed public relations and communication consultant, and also works as an adult education teacher as well as a trainer of adult education teachers. He has started teaching numeracy, because it was 'a meaningful expansion' of his other teaching activities in reading and writing. He sees mathematics primarily from an instrumental perspective -

doing maths in everyday life has to be quick, one has to have certain automatisms and techniques in order to be able to decide on the spot. It is useless if I don't know now what this polo shirt costs if it is reduced by $30 \%$.

While he is grateful that he can master maths and use it, he would not be sad if as of tomorrow it would no longer exist. As a linguist he feels he has 'a relatively high affinity for maths', and through starting to teach numeracy he has also become more interested in mathematical questions again. While language has 
grown and developed naturally, he considers maths to be more artificial, as it is shaped by conventions and specific decisions taken at various points in time -

I don't think it [maths] is something amazing. Because it didn't grow organically. There was always, somewhere, something was set down. Agreements. And such agreements are relatively rare in language.

Paul himself was always a very good student, in all subjects, but in high school 'maths moved further away with every semester and I became worse at it - with two exceptions, probability and sequences and series'. Overall, however, his school experiences did not leave him 'a traumatised type'. In the classroom he sees his role to be ' $a$ guide, a signpost through the three worlds of situations, concepts and numbers where I can intervene in a supportive manner and provide materials'. He aims at imparting

the dramaturgy of problems, where [students should start by] orienting themselves within the situation, the task, separating the important from the unimportant, identify what is asked of them, what they need and then, in the last 10\%, they calculate.

David (45 years old)originally trained as a commercial clerk in a bank from where he moved on to work with computers. When he realised that working with people was very important to him, he studied for four years to become a social worker. After working in this field for some years, he felt the need for change and moved into adult education. He started teaching numeracy 'because they needed someone who wanted to teach it.'

David is a reflective and intellectual person who finds mathematics fascinating and interesting. For him, 'maths is like a language [with which] you can create order in chaos ... you can explain certain things or find new dimensions in it and new understanding'. He is aware of his own limitations when it comes to understanding some aspects of mathematics, but also of human's limitations when creating it. He says that, 'there are two sides to mathematics: one is mathematics like it is taught at school, the concept and then the hidden application'.

When teaching he thinks it is very important to convey that mathematics is fun and to start from where the learners are. Mathematics should not stand at the centre, but solving problems should be the aim. David sees his tasks in the classroom to 'give 
inputs and accompany' students and it is important to him to be present and responsive, 'to discover it together [with the students], to go on a journey together'. In order to learn mathematics successfully, he thinks students should be 'open, also in maths where one is really moulded. I mean, the adults already shut down when they only hear the word'.

With regard to his own schooling, David's early years were somewhat problematic: he was sent to a special school (mostly due to behavioural problems), but remembers a moment some years later when 'it clicked somewhere and I was weeks ahead [...] the penny dropped and I changed to the higher level'. During his apprenticeship 'everything with maths was always easy, it was boring [...] I never studied and finished with 5.1 [out of 6]'.

From these short portraits a number of common experiences and shared characteristics can be identified:

- Overall the participants were good students and enjoyed school, including mathematics. However with the exception of David all experienced a time in their school career (usually in secondary school), when mathematics became more abstract and doing it was beyond their capacities.

- For all the participants, teaching numeracy was an addition to or extension of their language teaching activities. It was therefore not an intentional career move, but rather an extension of their previous activities - 'an extension I find that made a lot of sense' (Paul).

- With respect to teaching beliefs, all participants highly value individualised approaches to teaching and stress the importance of starting from their students' needs. They furthermore emphasise problem-solving as an important element of their numeracy classes.

In the next section, two specific aspects of the participants' experiences will be described in more detail. They include the participants' own experiences in school as well as their previous teaching experiences. Both of these aspects relate to the three identified characteristics and are considered to be crucial for the development and change of their beliefs.

\section{Specific biographical aspects}

While the participant's own school experiences did not leave any of them a traumatised person, all of them describe their own 
primary school experiences as what can be called traditional: teachercentred classes, focused on routines, with little activities from the students themselves and somewhat boring. This assessment is also reflected in comments the participants made about one of the video sequences which showed first grade children sitting on the floor and adding up points from a game that was presented as a mathematical activity: 'My school was completely different' (Lucy) or:

'Unfortunately I do not have such memories' (Daniel). More specifically, Paul says:

My memory of this time includes basic arithmetic at high speed. It had to be quick for me, time was important, already then [...] for six years I was the best student in the class.

And Kathrin makes a direct link between these experiences and her beliefs:

They [routines at school] influenced my belief that practising makes sense. Certain routines are not bad [...] the sense of achievement, of I know how to do it, I can apply it. For example elementary arithmetic, we practiced that a lot in primary school, with a strict teacher. And also today I'm still good at mental arithmetic.

Similarly, Lucy refers back to her own school experiences in secondary school, when she talks about her teaching:

I like doing mathematics and where it is beyond my comprehension, it can be stressful. It is of course no longer stressful, because I don't have to do it anymore, but it was a bit stressful once [...] and I can imagine that my participants, that they are stressed. They arrive at a point and can't go further [...] and that as a course leader it is important that you are aware that every person has his/her individual boundaries.

Lucy's statement also points to the second aspect which is relevant for the participants' beliefs, namely their previous teaching experiences in adult education:

When teaching adults, a lot is already set. Set by experiences, or bad experiences. There are only some wormholes which are open and provide access. New access. For me it is really about identifying these wormholes [...] but the walls are set and breaking them down with a sledgehammer does probably more damage than good. (Daniel)

Or: 
This is the start where children come in touch with mathematics. And if this goes wrong, then it's over. Then they are conditioned and that's it [...] and that's what I have today [people with] no interest in mathematics, who couldn't care less. (David)

Other phrases such as 'I know from my target audience that ...' (Lucy) or 'I noticed in previous classes that ...' (Daniel) indicate that the participants' previous experiences in teaching adults have become an integral part of their cognitive system.

Summing up these aspects, it can be said that the participants themselves experienced a traditional approach to teaching mathematics during their time as learners in primary school. Their experiences in secondary school were more mixed with clearly negative aspects such as the abstractness of mathematics and its irrelevance to everyday life becoming more acutely felt. Furthermore, their previous experiences of working with adults show how they perceive adult students as individuals who are very much shaped by their own previous school experiences and who therefore constitute a very specific target audience which clearly differs from school children and accordingly need to be taught differently. It is interesting to note that while the participants largely view their own school experiences positively, they seem to stress that most of their students come with negative experiences from their time at school, particularly with respect to mathematics.

\section{Mathematical and teaching beliefs}

While the description of the participants' teaching beliefs is mainly derived from their interview statements, their mathematical beliefs are largely derived from the visual and survey data. All participants were asked to present their views of mathematics in the form of a picture which was also discussed in the interviews. Both visual and verbal data indicate that the participants' dominant mathematical view is that of the problem solving perspective, as they contain evidence for both autonomous mathematical activities and the development of mathematics (two of the characteristics described by Rolka and Halverscheid 2011). However, the two characteristics for the instrumentalist perspective are also represented to a considerable extent, namely in the form of non-coherent sequences and conceptions of the usefulness and application of mathematics in everyday life. 
Kathrin's picture is presented as example in Figure 1 below. It shows the problem solving perspective, for example, in the form of the graphs and maps, and the instrumentalist through specific items such as the receipt and the different formulae which are not connected. As Kathrin's picture shares many characteristics (particularly its collage form and use of artefacts) with the other pictures, it can be considered to be somewhat representative for all the images created by the participants of this study (for a full discussion of all images see Beeli-Zimmermann 2014). It also needs to be mentioned that when talking about the picture, it became quickly clear that also for these participants mathematics is different from and more than numeracy:

[When working on it] my training as numeracy teacher interfered, because it is the most recent, but then I always thought, no, it is not only every day mathematics, she [the author] wants to know something about maths. (Kathrin)

However, it is equally evident, that at least for some, the two are almost identical: 'For me mathematics is primarily everyday mathematics' (Paul).

\section{Figure 1: Kathrin's picture of mathematics}

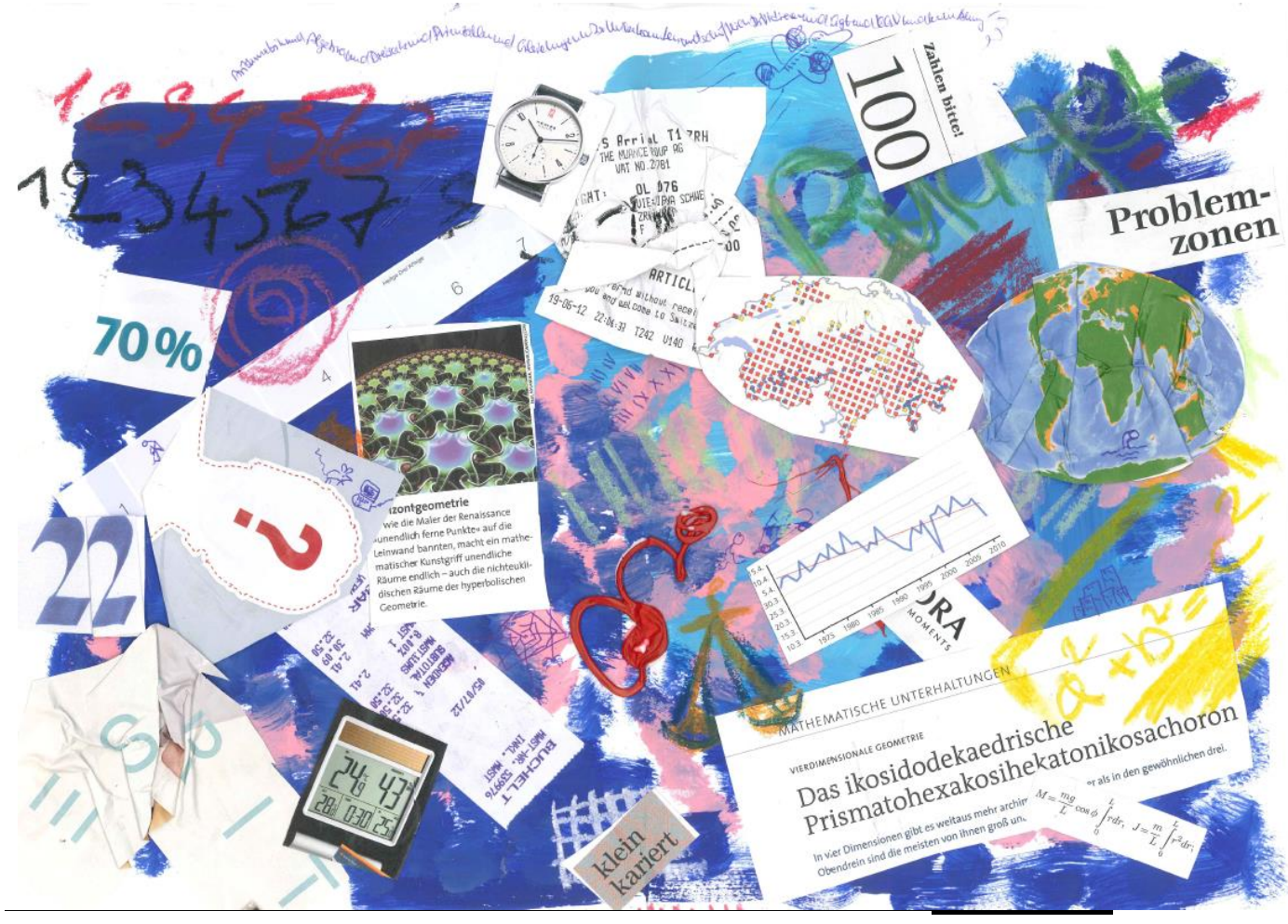


More broadly speaking, therefore, a dynamic view of mathematics, which is characterised by process and application (Grigutsch and Törner 1998) can be identified for all participants. Ernest's (1989) Platonist view is almost completely absent. However, the participants' pictures also express a number of aspects of mathematics which cannot easily be reconciled with Ernest's (1989) perspectives, namely specific characteristics of mathematics, such as its aesthetic, its profoundness (which Kathrin chose to represented by the blue colour she used in the background), its relationship with language or the participant's emotional relationship with mathematics. Issues such as these complement the dynamic view descrived by Ernest and reflected in the participants' pictures and statements and indicate that indeed mathematical beliefs go beyond purely cognitive aspects.

When looking at the participants' teaching beliefs, their clear preferences for constructivist approaches are noteworthy. This is for example reflected in how they see their role as teacher, which they consider to be that of 'a coach, an opener' (Daniel), 'a listener, I listen to where the shoe pinches' (Kathrin) or 'a guide or signpost' (Paul). Furthermore they are all very supportive of individualised approaches and stress the importance of starting from the students' perspective: 'I very much like to work on an individualised basis and that is simply necessary, because otherwise half of them are bored' (Lucy). Or: 'the participants are my clients, and to meet them where they are [is my task]' (David). Other indicators for their constructivist views are the fact that they hardly use textbooks and existing material but generally develop new materials or use materials that are available in the teaching situation. It is also worth noting that most of the participants stress that teaching everyday mathematics is different from teaching mathematics and teaching adults is different from teaching children:

It is not a school context, because children all know the same, more or less. In $5^{\text {th }}$ grade you know what they already had and what is new [...] but these people they have different levels of German, they might have had none or nine years of school, maybe even some vocational training [...] they have nothing in common except that they are in the same class. (Lucy) 
Additionally, 'adults are situated in very different life contexts. When working with adults, money is very quickly an issue, it is a big and very central theme for everyday mathematics' (Kathrin).

The participants' constructivist preferences as identified in the verbal data, are also reflected in their quantitative answers, where they show a clear preference for the discovery approach as it is described by Swan (2006). Furthermore, the participants differ in significant ways from Swan's original population (teachers from further education colleges in England) in this and one other dimension, namely transmission (see table 1 below). The significance of the differences was established using the Mann-Whitney U-test (transmission: $\mathrm{U}=26, \mathrm{p}<.001$ and discovery: $\mathrm{U}=285, \mathrm{p}<.01$; detailed results of the survey will be reported elsewhere, Beeli-Zimmermann under review). As the two populations can otherwise be considered to be quite alike with respect to their work context and diverse educational backgrounds, these differences are noteworthy.

Table 1: Comparison of Swan's (2006) data and the participants of this study

$\begin{array}{lcccc}\text { Dimension } & \begin{array}{l}\text { Swan (2006) } \\ (\mathrm{N}=64)\end{array} & & \begin{array}{l}\text { This study } \\ (\mathrm{N}=5)\end{array} & \\ & \begin{array}{l}\text { Mean } \\ \text { weighting }\end{array} & \text { SD } & \begin{array}{c}\text { Mean } \\ \text { weighting }\end{array} & S D \\ \text { Transmission } & 40.4 & 17.3 & \mathbf{1 6} & 6.62 \\ \text { Discovery } & 30.8 & 10.0 & \mathbf{4 6 . 7} & 8.07 \\ \text { Connectionist } & 28.8 & 12.1 & 37.3 & 10.7\end{array}$

In short, the participants' beliefs show characteristics of both the instrumental and problem solving view of mathematics and they clearly prefer constructivist approaches to teaching. They furthermore stress that they are teaching everyday mathematics and that this is different from teaching mathematics. These results will now be integrated and discussed in the next section.

\section{Discussion}

In line with Taylor's observation that 'the past shapes the present' (Taylor 2003:75), it is also possible to identify some similarities between the personal experiences and the mathematical 
beliefs of this group of teachers. More specifically, the following links can be made:

- The participants' dynamic view of mathematics stressing process and application can on one hand be related to their own school time where they often experienced a focus on an instrumental approach to mathematics, namely practising skills and routine. On the other hand, their work context, which is clearly focused on providing students with skills relevant for their everyday life, can explain the importance of applications or more specifically problem solving skills.

- The participants' positive experiences at primary school are reflected in their fundamentally positive attitude towards mathematics (with the exception of Daniel who says of himself that he is very ambivalent towards mathematics). Many of the participants enjoy problem solving and puzzles and consider it important to also enable their students (who often come with negative experiences to their classes) to have these positive experiences and the associated feeling of success.

- When looking at the participants' more ambivalent experiences they had during secondary school it is interesting to note that to some extent this is also reflected in their mathematical beliefs. The participants see mathematics as being divided into an applied, practical part and an abstract, conceptual part. The former is what they focus on in their classes and what they consider themselves to be good at; the latter is what they consider to be mathematics and largely beyond their skills.

- The clear constructivist teaching preferences seem to mainly derive from their previous experiences as adult education teachers where they have experienced the specificities of teaching adult students with previous learning histories. The participants strongly advocate individualised approaches when teaching adults which reflect the heterogeneous classes they work with.

Many of these findings were to be expected: Skott (2009) or Beswick (2013) also stress the relevance of context for beliefs and Beswick (2012) also observed that teachers hold different views of mathematics as a field and as a school subject. However, there is one 
aspect of the presented data which is noteworthy: in spite of their predominantly traditional own school experiences and an identified relevance of an instrumental belief of mathematics, the participants of this study express typical constructivist teaching beliefs and it seems unlikely that they teach numeracy the way they were taught mathematics (as no classroom observation was undertaken for this study this assessment remains speculative). In this respect the participants of this study also clearly differ from what Taylor found, namely that his adult education teacher showed 'little discrepancy from [...] their past school lives and their present beliefs about teaching adults' (Taylor 2003:75). And while the difference between everyday mathematics and school mathematics can be considered one important element accounting for this unexpected constructivist dominance, there are two other possible explaining influences, namely their previous experience as adult education teachers and their training as numeracy teachers.

In their role as adult literacy teachers, they have already acquired teaching beliefs with respect to this target audience and it is likely that they transfer this experience to the new content area they also teach, namely everyday mathematics. This factor might also explain that in spite of their otherwise heterogeneous education and experiences, the participants' mathematical and teaching beliefs are remarkably similar. Similarly, they have all undergone the same training as numeracy teachers, which constitutes therefore another possible influence in the formation and change of the participants beliefs about teaching numeracy. As the transfer of their previous teaching experiences constituted a significant part of their numeracy trainings (oral communication by the course leader), these two aspects are difficult to separate in this sample and clearly need further investigation.

In spite of the limitations of this study - particularly the small sample, their homogeneity with respect to their current work context and their training as well as the lack of information on how the participants actually act in the classroom due to the absence of observed lessons - its results clearly point towards the relevance of practical experiences for the change of teachers' beliefs and therefore support similar earlier findings (for example Brosnan 1994 and Clarke 1994, both cited in Nisbet and Warren 2000:35). However, in order to better understand the specific processes of belief formation and change, long-term studies focusing on distinct aspects for 
example the integration of previous experiences in further training, would be needed.

Approaches such as patterns-of-participation as it is presented by Skott (2011) seem promising in this respect, as they move away from simple belief inventories towards more integrated perspectives. Skott proposes to 'disentangle patterns in the teacher's reengagement in other past and present practices in view of the ones that unfold at this instant' (Skott 2014:24). Such a perspective not only takes interactions in the classroom into account, but also exchanges between colleagues or with other key actors of a particular context. This approach could therefore potentially also shed light on possible differences that teachers express with respect to numeracy and mathematics, as they might discuss one field with students and another in the context of some training or a meeting. Differentiating beliefs according to specific areas of mathematics such as problem solving or geometry has been done before (Pehkonen 2008) and it seems likely that specific aspects such as problem solving might be more important in one of them. Either way, researching adult education teachers' interactions from a more wholistic and long term perspective, particularly under close consideration of their previous teaching and training experiences, seems to be a promising approach for belief research in general and could contribute to learning more about the formation and change of beliefs. Ideally it would go beyond identifying similarities between teachers' previous experiences and their current beliefs - as it was done in this article and many other studies - and be able to describe processes or interactions explaining the (possibly causal) relationship between these similarities.

\section{Endnotes}

1 The field of adult education in Switzerland is very heterogeneous, due to the decentralised organisation of the education system on one hand and the strong stance of vocational training on the other hand. The basic degree in adult education (called SVEB 1) corresponds to 13.5 credit points (ECTs) in the European credit system and demands a minimum of $150 \mathrm{hrs}$ of taught classes. It is aimed at people who work part time as teachers and trainers. An English summary of the Swiss system for teachers and trainers in further education can be found here: http://www.alice.ch/en/ada/certificatesveb/?tx_damdownloadcenter_pi $1 \% 5 \mathrm{Bfile} \% 5 \mathrm{D}=4851 \& \mathrm{cHash}=\mathrm{e}$ 
760b9c1498dc194f91051431916dd7d (retrieved October 3, 2014).

2 The network currently has some 112 members. More information about it is available in German at: http://www.netzwerkalltagsmathematik.ch/ (last accessed 14 Sept 2014).

3 The initial idea of eliciting and identifying critical incidents during their own school time through the use of videos did not work out as intended. When seeing the videos, the participants frequently commented that their own school time was nothing like what was shown, however theywere rarely in a position to identify specific critical memories from their time as students. Most of the participants said that they did not remember much from their own school time, which was some 40 to 50 years back for them.

\section{References}

Ambrose, R (2004) Initiating Change in Prospective Elementary School Teachers' Orientations to Mathematics Teaching by Building on Beliefs, Journal of Mathematics Teacher Education, vol 7, no 2, pp 91-119. doi: http://dx.doi.org/10.1023/B:JMTE.0000021879.74957.63

Andrews, P \& Hatch, G (1999) A New Look at Secondary Teachers' Conceptions of Mathematics and Its Teaching, British Educational Research Journal, vol 25, no 2, pp 203-223. doi: http://dx.doi.org/10.1080/0141192990250205

Askew, M, Rhodes, V, Brown, M, William, D \& Johnson, D (1997) Effective Teachers of Numeracy: Report of a study carried out for the Teacher Training Agency, King's College, University of London, London.

Beeli-Zimmermann, S (2014), Beyond Questionnaires - Exploring adult education teachers' mathematical beliefs with pictures and interviews, Adults Learning Mathematics - An International Journal, vol 9, no 2, pp 35-53.

Beeli-Zimmermann, S (under review), Extending Belief Research to Adult Basic Education: An exploration of adult educators' beliefs about mathematics and its teaching.

Ball, D (1988) Unlearning to teach mathematics, For the Learning of Mathematics, vol 8, no 1, pp 40-48.

Barkatsas, A, and Malone, J (2005) A typology of mathematics teachers' beliefs about teaching and learning mathematics and 
instructional practices, Mathematics Education Research Journal, vol 17, no 2, pp 69-90. doi:

http://dx.doi.org/10.1007/BF03217416

Berger, P (1999) The Hidden Dimension in Maths Teaching and Learning Processes - Exploring entrenched beliefs, tacit knowledge, and ritual behaviour via metaphors, in Proceedings of the Eighth European MAVI Workshop on Mathematical Belief Research, University of Cyprus, Nicosia, pp 1-10.

Beswick, K (2003) Accounting for the Contextual Nature of Teachers' Beliefs in Considering Their Relationship to Practice, in Mathematics education research: Innovation, networking, opportunity. Proceedings of the 26th Annual Conference of the Mathematics Education Research Group of Australasia, MERGA, Geelong, pp 152-159.

Beswick, K (2012) Teachers' Beliefs about School Mathematics and Mathematicians' Mathematics and their Relationship to Practice, Educational Studies in Mathematics, vol 79, no 1, pp 127-147. doi: http://dx.doi.org/10.1007/s10649-011-9333-2

Blömeke, S, Müller, C, Felbrich, A \& Kaiser, G (2008)

Epistemologische Überzeugungen zur Mathematik, in Blömeke,S, Kaiser, G \& Lehmann, R, eds, Professionelle Kompetenz angehender Lehrerinnen und Lehrer. Wissen, Überzeugungen und Lerngelegenheiten deutscher Mathematikstudierender und-referendare. Erste Ergebnisse zur Wirksamkeit der Lehrerausbildung Waxmann, Münster, pp 219-246.

Bulmer, M \& Rolka, K (2005) The 'A4-Project'- Statistical world views expressed through pictures, in Proceedings of the 29th Conference of the International Group for the Psychology of Mathematics Education, PME, Melbourne, pp 2-193-2-200.

Calderhead, J (1996) Teachers: Beliefs and Knowledge, in Berliner, D C \& Calfee, RC, eds, Handbook of Educational Psychology, Macmillan Library Reference, New York, London, pp 709-725. Condelli, L (2006) A Review of the Literature in Adult Numeracy: Research and Conceptual Issues, American Institutes for Research, Washington DC.

Dirkx, JM, Spurgin, ME (1992) Implicit Theories of Adult Basic Education Teachers: How their beliefs about students shape classroom practice, Adult Basic Education, vol 2, no 1, pp 2041. 
Ernest, P (1989) The Knowledge, Beliefs and Attitudes of the Mathematics Teacher: A model, Journal of Education for Teaching, vol 15, no 1, pp 13-33. doi: http://dx.doi.org/10.1080/0260747890150102

Forgasz, H \& Leder, GC (2008) Beliefs about Mathematics and Mathematics Teaching, in Sullivan, P \& Wood, T, eds, The International Handbook of Mathematics Teacher Education. Volume 1: Knowledge and beliefs in Mathematics Teaching and Teaching Development, Sense Publishers, Rotterdam, pp 173192.

Furinghetti, F \& Pehkonen, E (2002) Rethinking Characterization of Beliefs, in Leder GC, Pehkonen, E \& Törner, G, eds, Beliefs. A hidden variable in mathematics education? Kluwer Academic Publishers, Dordrecht, Boston, pp 39-57.

Goldin, GA, Rösken, B \& Törner, G (2009) Beliefs - no longer a hidden variable in mathematical teaching and learning processes, in Maasz J \& Schlöglmann W, eds, Beliefs and attitudes in mathematics education. New research results, Sense Publishers, Rotterdam, pp 1-18.

Grigutsch, S, Raatz, U \& Törner, G (1998) Einstellungen gegenüber Mathematik bei Mathematiklehrern, Journal für MathematikDidaktik, vol 19, pp 3-45. doi: http://dx.doi.org/10.1007/BF03338859

Handal, B (2003) Teachers' Mathematical Beliefs: A review, The Mathematics Educator, 13(2), 47-57.

Handal, B \& Herrington, A (2003) Mathematics Teachers' Beliefs and Curriculum Reform, Mathematics Education Research Journal, vol 15, no 1, pp 59-69. doi: http://dx.doi.org/10.1007/BF03217369

Hannula, MS, Portaankorva-Koivisto, P, Laine, A \& Näveri, L, eds, (2012) Current State of Research on Mathematical Beliefs XVIII: Proceedings of the MAVI-18 Conference. Finnish Research Association for Subject Didactics, Helsinki.

Henningsen, I \& Wedege, T (2003) Values and Mathematics: Attitudes among Teachers in Adult Education, in Learning Mathematics to Live and Work in our World. Proceedings of the 10th International Conference on Adults Learning Mathematics, Universitätsverlag Trauner, Linz, pp 110-118.

Kaasila, R, Hannula, MS, Laine, A \& Pehkonen, E (2006) Autobiographical Narratives, Identity and View of 
Mathematics, in European Research in Mathematics Education $I V$. Proceedings of the Fourth Congress of the European Society for Research in Mathematics Education, Universitat Ramon Llull, Barecelona, pp 215-224.

Leder, GC, Pehkonen, E \& Törner, G, eds, (2002a) Beliefs: A hidden variable in mathematics education? Kluwer Academic Publishers, Dordrecht, Boston. doi: http://dx.doi.org/10.1007/0306-47958-3

Leder, GC, Pehkonen, E \& Törner, G (2002b) Setting the Scene, in Leder G C, Pehkonen, E and Törner, G, (eds), Beliefs. A hidden variable in mathematics education? Kluwer Academic Publishers, Dordrecht, Boston, pp 1-10. doi: http://dx.doi.org/10.1007/0-306-47958-3

Mayring, P (2000) Qualitative Content Analysis. Forum Qualitative Sozialforschung / Forum: Qualitative social research, vol 1, no 2, Art. 20, 28 paragraphs.

Mayring, P (2013) Qualitative Content Analysis - Theoretical foundation and basic procedures (forthcoming soon).

Millsaps, GM (2000) Secondary Mathematics Teachers' Mathematics Autobiographies: Definitions of mathematics and beliefs about mathematics instructional practice, Focus on Learning Problems in Mathematics, vol 22, no 1, pp 45-67.

Nisbet, S \& Warren, E (2000) Primary School Teachers' Beliefs Relating to Mathematics, Teaching and Assessing Mathematics and Factors that Influence these Beliefs, Mathematics Teacher Education and Development, vol 2, pp 34-47.

O’Donoghue, J (2002) Numeracy and Mathematics, Irish Math Society Bulletin, vol 48, pp 47-55.

OECD (2013) OECD Skills Outlook 2013: First results from the Survey of Adult Skills, OECD Publishing, Paris.

Oksanen, S \& Hannula, MS (2012) Finnish Mathematics Teachers' Beliefs about their Profession Expressed through Metaphors, in Current State of Research on Mathematical Beliefs XVIII. Proceedings of the MAVI-18 Conference, Finnish Research Association for Subject Didactics, Helsinki, pp 315-326. Pajares, MF (1992) Teachers' Beliefs and Educational Research: Cleaning up a messy construct, Review of Educational Research, vol 62, no 3, pp 307-332. doi: http://dx.doi.org/10.3102/00346543062003307 
Pehkonen, E (2008) State-of-the-art in Mathematical Beliefs Research: Presentation at the 10th International Congress on Mathematical Education, in Proceedings of the 10th International Congress on Mathematical Education. ICME 10 2004, IMFUFA, Department of Science, Systems and Models, Roskilde University, Roskilde, pp 1-14.

Pehkonen, E \& Törner, G (2004) Methodological Considerations on Investigating Teachers' Beliefs of Mathematics and its Teaching, Nordisk matematikkdidaktikk, vol 9, no1, pp 21-49.

Perkkilä, P (2003) Primary School Teachers' Mathematics Beliefs and Teaching Practices, in Proceedings of the Third Conference of the European Society for Research in Mathematics Education, University of Pisa, Bellaria, pp 1-8.

Pratt, DD (1992) Conceptions of Teaching. Adult Education Quarterly, vol 42, pp. 203-220.

Raymond, AM (1997) Inconsistency between a Beginning Elementary School Teacher's Mathematics Beliefs and Teaching Practice, Journal for Research in Mathematics Education, vol 28, no 5, pp 550-576. doi: http://dx.doi.org/10.2307/749691

Rolka, K, and Halverscheid, S (2011) Researching Young Students' Mathematical World Views, Zentralblatt für Didaktik der Mathematik, vol 43, no 4, 521-533. doi: http://dx.doi.org/10.1007/s11858-011-0330-9

Richardson, L \& St. Pierre, EA (2005) Writing. A method of inquiry, in Denzin, N K and Lincoln, Y S, eds, The SAGE handbook of qualitative research, 3rd ed, Sage Publications, Thousand Oaks, pp 959-978.

Schlöglmann, W (2007) Beliefs Concerning Mathematics Held by Adult Students and their Teachers, in Current State of Research on Mathematical Beliefs XII. Proceedings of the MAVI-7 workshop, Department of Teacher Education University of Helsinki, Helsinki, pp 97-109.

Skott, J (2009) Contextualising the Notion of 'Belief Enactment', Journal of Mathematics Teacher Education, vol 12, no 1, pp 27-46. doi: http://dx.doi.org/10.1007/s10857-008-9093-9

Skott, J (2011) Beliefs vs. Patterns of Participation - Towards coherence in understanding the role the teacher, in Rösken, B and Casper, $\mathrm{M}$ eds, Current state of research on mathematical beliefs XVII. Proceedings of the MAVI-17 Conference, 
Professional School of Education, Ruhr-Universität Bochum, Bochum, pp 211-220.

Skott, J (2014) The Promises, Problems and Prospects of Research on Teachers' Beliefs, in Fives, $\mathrm{H}$ and Gill, M G, eds, International handbook of research on teachers' beliefs, Routledge, New York, pp 13-30.

Speer, NM (2005) Issues of Methods and Theory in the Study of Mathematics Teachers' Professed and Attributed Beliefs, Educational Studies in Mathematics, vol 58, no 3, pp 361-391. doi: http://dx.doi.org/10.1007/s10649-005-2745-0

Stone, R (2009) 'I, robot' Free Will and the Role of the Maths Teacher - Who decides on how we teach? in Numeracy Works for Life. Proceedings of the 16th International Conference of Adults Learning Mathematics, London Southbank University, London, pp 246-253.

Swain, J \& Swan, M (2009) Teachers' Attempts to Integrate Research-based Principles into the Teaching of Numeracy with Post-16 Learners, Research in Post-Compulsory Education, vol 14, no 1, pp 75-92. doi: http://dx.doi.org/10.1080/13596740902717424

Swan, M (2006) Designing and Using Research Instruments to Describe the Beliefs and Practices of Mathematics Teachers, Research in Education, vol 75, no 1, pp 58-70. doi: http://dx.doi.org/10.7227/RIE.75.5

Taylor, E (2002) Using Still Photography in Making Meaning of Adult Educators' Teaching Beliefs, Studies in the Education of Adults, vol 34, no 2, pp 123-139.

Taylor, E (2003) The Relationship Between the Prior School Lives of Adult Educators and Their Beliefs about Teaching Adults, International Journal of Lifelong Education, vol 22, no 1, pp 59-77. doi: http://dx.doi.org/10.1080/02601370304828 unterrichtsvideos.ch, ed, (2008ff) Eine Videoplattform für die Lehrerinnen- und Lehrerbildung, Retrieved 1 Jul 2014 from http://www.unterrichtsvideos.ch.

van Zoest, L R, Jones, G A, and Thornton, C A (1994) Beliefs about Mathematics Teaching Held by Pre-Service Teachers Involved in a First Grade Mentorship Program, Mathematics Education Research Journal, vol 6, no 1, pp 37-55. doi: http://dx.doi.org/10.1007/BF03217261 


\title{
Annex 1: Instructions for the creation of the picture
}

Ten days before the first interview the participants received a letter asking them to create a picture with the following specifications: "Imagine you were an artist and have accepted the following contract work: What is mathematics? A personal view. Present your views in a pictorial, creative manner, working with materials and techniques of your choice (coloured pencils, watercolour, collage, etc.)." (translation by the author).

Together with this task they received an A3-format piece of paper, which they had to use for the creation and presentation of their picture and a post-paid envelope in which they could return their creation. They were asked to return the picture to the author no later than two days before the first meeting, as it was the basis for the first interview.

\section{Annex 2: Survey taken from original questionnaire by Swan(2006)}

Instruction for the questionnaire: 'Give each statement a percentage, so that the sum of the three percentages in each section is 100' (Swan 2006:60)

\author{
Compo- Statement \\ nent \\ Mathematics is: \\ MT A given body of knowledge and standard procedures \\ A set of universal truths and rules which need to be conveyed to students \\ MD A creative subject in which the teacher should take a facilitating role, \\ allowing students to create their own concepts and methods \\ MC An interconnected body of ideas which the teacher and the student \\ create together through discussion \\ Learning is: \\ LT An individual activity based on watching, listening and imitating until \\ fluency is attained \\ LD An individual activity based on practical exploration and reflection \\ LC An interpersonal activity in which students are challenged and arrive at \\ understanding through discussion \\ Teaching is: \\ TT Structuring a linear curriculum for the students; giving verbal \\ explanations and checking that these have been understood through \\ practice questions; correcting misunderstandings when students fail to \\ 'grasp' what is taught \\ TD Assessing when a student is ready to learn; providing a stimulating \\ environment to facilitate exploration; avoiding misunderstandings by the
}




\section{Compo- Statement}

nent

careful sequencing of experiences

TC A non-linear dialogue between teacher and students in which meanings and connections are explored verbally. Misunderstandings are made explicit and worked on

The first letter in the first column represents Mathematics (M), Learning (L) or Teaching (T). The second letter refers to Transmission (T), Discovery (D) or Connectionist (C) beliefs.

The transmission, discovery and connectionist dimensions are calculated by the mean weightings of MT, LT, TT, respectively f MD, LD, TD and MC, LC, TC.

\section{Annex 3: Coding scheme for pictures (Rolka and Halverscheid 2011)}

View Characteristic

Non-coherent sequences

Facile conception of usefulness/application of mathematics in the course of life

Display of mathematical coherence

Theory/history of mathematics

\section{Description}

- Are there several objects within the work which belong to a particular field of mathematics but do not show any relation with one another?

- Does the text consist of an enumeration or a classification of items rather than showing the parallels in-between?

- Essential: the items instead of their characteristics are considered to be important, that is, the items are more important than their meaning in a wider context

- Is there a slight evidence of the importance of mathematics and its application?

- Is the attention drawn to the fact that applications are useful rather than in which way?

- Essential: the central motivation point for practicing mathematics is the convenience one can gain where the character of usefulness always comes to the fore

- Are there any references drawn between any mathematical items in the work?

- Does the text show a cohesive character within the implementations?

- Essential: relations are identified but not necessarily self-drawn

- Is the development of mathematics referred to as a determined, somewhat stable construct of knowledge? 
View Characteristic

Autonomous

mathematical activities

The development of mathematics

\section{Description}

- Are scholars who once made mathematics crucial to the work?

- Is there an attempt to constitute a part of mathematics as methodical?

- Essential: mathematics as a static entity predetermined by nature

- Does the setting of tasks offer the occasion for using mathematics actively and self-dependently?

- Do certain actions enclose mathematical items as well and are not mentioned without any reference? - Essential: not only meta-mathematical

explanations, but something inventive; an extract out of a mathematical process allowing not only to counterfeit, but also permitting independent thinking.

- Is the development of mathematics indicated by being a process?

- Does the description transcend the image of mathematics being a complete and static product? - Is there somebody mentioned who actually produces mathematics?

- Essential: dynamic of mathematics (through the author or somebody else) is described as a process 